\title{
Fatigue behaviour of Plasma Sprayed Titania and Chromia Coatings
}

\author{
Angelos Koutsomichalis ${ }^{1}$, Antonios Lontos ${ }^{2}$, George Loukas ${ }^{1}$, Michalis Vardavoulias ${ }^{3}$, \\ and Nikolaos Vaxevanidis ${ }^{4 *}$ \\ ${ }^{1}$ Hellenic Air-Force Academy, Department of Aeronautical Studies, TGA 1010, Attica, Greece \\ ${ }^{2}$ Frederick University, School of Engineering, Nicosia 1036, Cyprus \\ ${ }^{3}$ Pyrogenesis S.A, Technological Park of Lavrio, GR 195 00, Lavrio, Greece \\ ${ }^{4}$ School of Pedagogical \& Technological Education, GR 151 22, Heraklion, Greece
}

\begin{abstract}
Cr}_{2} \mathrm{O}_{3}$ and $\mathrm{TiO}_{2}$ powders were deposited by atmospheric plasma spray (APS) on steel substrates. Microstructural analysis of the coatings showed typical lamellar structure with good coating quality. Fatigue strength was studied by using cyclic testing (measuring with an inhouse-built apparatus the strength of the coated systems under a wide range of impact cycles) and static loading tests (Vickers tests standards with $600 \mathrm{~N}$ and $1500 \mathrm{~N}$ ) measuring the adhesion properties of the coatings. In low cycles $\left(1 \times 10^{3}\right)$ Titania coatings exhibited better strength, while at intermediate $\left(4.5 \times 10^{5}\right)$ and high $\left(1 \times 10^{6}\right)$ number of impact cycles, both Chromia and Titania coatings exhibited quite similar strength characteristics. At low impact force the thickness of the coatings plays critical role with better performance obtained by Chromia coatings. During static loading both coatings exhibited similar characteristics at the crater diameter but with larger crater depth for Titania. Chromia coatings exhibited higher strength resistance than Titania coatings with better mechanical properties and coating structure.
\end{abstract}

\section{Introduction}

The coating technology has the advantage of combining two dissimilar materials to improve, in a synergistic way, the performance of the whole. Plasma spray, one of the most common deposition techniques for thick coatings, is characterized by a set of unique features, such as the wide range of materials, homogeneous coatings, fine microstructures, high deposition rate and a process being performed in any conceivable environment [1, 2].The purpose of this study is to study the fatigue properties of $\mathrm{Cr}_{2} \mathrm{O}_{3}$ (Chromia) and $\mathrm{TiO}_{2}$ (Titania) coatings. Chromium oxide $\left(\mathrm{Cr}_{2} \mathrm{O}_{3}\right)$ based materials have been used to improve the scuff resistance [3, 4] and enhance corrosion resistance [5]. Plasma sprayed Titania $\left(\mathrm{TiO}_{2}\right)$ coatings are used in applications like bearings and pump seals and are characterized by sufficient microhardness (approx. 8GPa), relatively high density and adhesion to metallic substrates $[6,7]$.

A rather limited number of research studies have been carried out on the fatigue behaviour of plasma sprayed coated specimens with conflicting findings relative to the 
influence of coatings on the fatigue life either enhancement [8,9] or debit [10,11]. Some studies investigate the effect of substrate preparation prior to coating deposition, such as shot peening or grit blasting, which are considered as residual stress contributors mitigating fatigue debits incurred by coating application [12] or attempt to isolate the coating's influence on fatigue life [13].

Considering that coating properties are highly dependent on their processing parameters $[14,15]$, some works try to assess the coating process parameters on the fatigue behaviour of thermally sprayed coated specimens $[11,16]$.

This paper focuses on the fatigue behaviour of chromia and titania plasma sprayed coatings, introducing a unique fatigue tester and seeks to address the relation of coating application and structure on their fatigue behaviour in an effort to elucidate prior findings. This work is a part of a wider research work on the wear and mechanical properties of these coatings.

\section{Experimental}

A commercially available chromia (METCO 106) and titania powder (AMPERIT 782) were deposited on the surface of structural steel substrates $(0.60 \%$ wt $\mathrm{C}, 0.40 \%$ wt $\mathrm{Si}$, $0.75 \%$ wt $\mathrm{Mn}, 0.035 \%$ wt $\mathrm{P}$ and $0.0035 \%$ wt $\mathrm{S})$. The chromia powder $\left(\mathrm{Cr}_{2} \mathrm{O}_{3}: 95 \%, \mathrm{TiO}_{2}\right.$ : 4.25\%, $\mathrm{Fe}_{2} \mathrm{O}_{3}: 0.25 \%, \mathrm{SiO}_{2}: 0.5 \%, \mathrm{Al}_{2} \mathrm{O}_{3}$ 0.25\%, all other: $0.5 \%$ ) had particle size $90+11 \mu \mathrm{m}$ and angular/blocky morphology while the also angular/blocky titania powder ( $\mathrm{TiO}_{2}: 99 \%$, $\mathrm{Fe}_{2} \mathrm{O}_{3}$ : $0.25 \%, \mathrm{SiO}_{2}: 0.3 \%$ ) had particle size distribution of $-90+45 \mu \mathrm{m}$. Fatigue test specimens were prepared with $45 \mathrm{~mm}(\mathrm{~L}), 35 \mathrm{~mm}(\mathrm{~W})$, and $2.5 \mathrm{~mm}(\mathrm{H})$.

Prior to the APS, the steel substrates were grit blasted by alumina with $0.8-1 \mathrm{~mm}$ grain sizes to achieve roughness of approximately $\mathrm{Ra}=8 \mu \mathrm{m}$. After sandblasting, samples were cleaned in an ultrasound bath with acetone for $5 \mathrm{~min}$ and dried with compressed air. Cleaned samples were vacuum packed and conserved in a dryer at $60^{\circ} \mathrm{C}$ until coating deposition.

Nickel Aluminide (METCO 404NS) powder was used as bond coating with a thickness of $80 \mu \mathrm{m}$. The thicknesses of the deposits in each specimen were $100 \mu \mathrm{m}, 200 \mu \mathrm{m}, 250 \mu \mathrm{m}$, $350 \mu \mathrm{m}$ respectively.

The coatings were deposited by APS gun (FST SG-100 80kW) fitted to a KUKA robotic arm. The spraying conditions are shown in Table 1.

Table 1. Spraying parameters

\begin{tabular}{|c|c|c|c|}
\hline Spraying Parameter & Cr2O3 & TiO2 & Ni-Al bond coat \\
\hline Voltage (V) & 37,5 & 38,5 & 50 \\
\hline Current (A) & 600 & 500 & 450 \\
\hline Pressure Argon (psi) & 120 & 120 & 120 \\
\hline Pressure Hydrogen (psi) & 11 & 11 & 9 \\
\hline Spraying distance (mm) & 100 & 100 & 100 \\
\hline Spray rate (mm/sec) & 450 & 450 & 450 \\
\hline Step (mm) & 5 & 5 & 5 \\
\hline
\end{tabular}


A B071 Olympus optical microscopy and JEOL JSM-63000 scanning electron microscope were used for the microstructural analysis. X-ray diffraction (XRD) analysis was performed $\left(\mathrm{Cu} \mathrm{Ka}\right.$ radiation with a wave length of $\left.1.5418^{\circ} \mathrm{A}\right)$.

Fatigue strength of the chromia and titania coatings was studied using cyclic and static loading. Cyclic testing was performed using an in-house-built fatigue tester (Fig. 1) applying $1 \times 10^{3}, 4.5 \times 10^{5}$ and $1 \times 10^{6}$ impact cycles. The force was constantly monitored using a HBM Type U3 50KN load cell connected to a computer. The fatigue tester provided sinusoidal impact of amplitude $100 \mathrm{~N}$ and $250 \mathrm{~N}$ at $50 \mathrm{~Hz}$.

After the fatigue tests, the diameter of the remaining imprints was investigated by means of an optical AmScope microscope, while the depth of the remaining imprints was measured using a Taylor Hobson PRECISION roughness tester. The coatings adhesion were studied under static loading using a Mitutoyo Hardness Testing Machine. For the investigations, the hardness Vickers test specifications were taken into consideration. Briefly, the Vickers test is characterized by the indentation of a conical indenter with angle $\alpha=136^{\circ}$ onto the specimen. For the Vickers tests, two indentation loads were implemented, $600 \mathrm{~N}$ and $1500 \mathrm{~N}$.

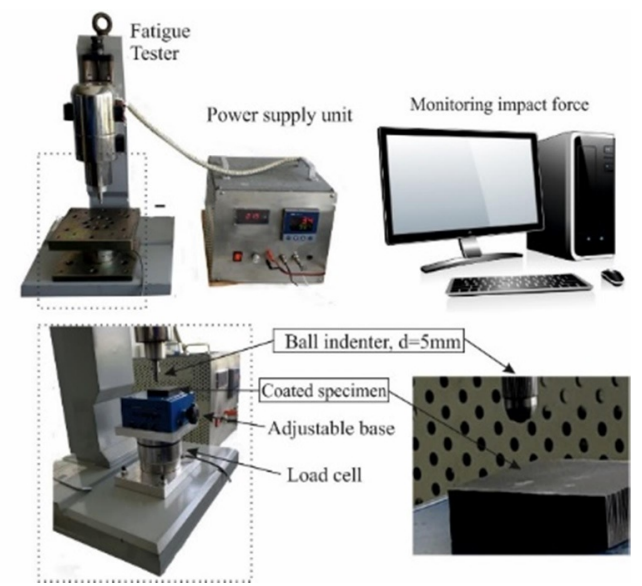

Fig. 1. Fatigue tester and experimental procedure

\section{Results and discussion}

\subsection{Coatings microstructure}

Fig. 2 shows that the micrograph of chromia coating which appears with the typical, for plasma sprayed deposits, lamellar structure. The microstructure exhibited some interlamellar defects and intra-lamellar cracks, attributed to splat quenching. The black spots are rounded pores, due to gas entrainment and imperfect stacking between splats. Porosity was measured approximately to $7 \%$. No unmelted particles were found, the coating is rather homogeneous and coating-bond coating-substrate interfaces reveal good cohesion. 


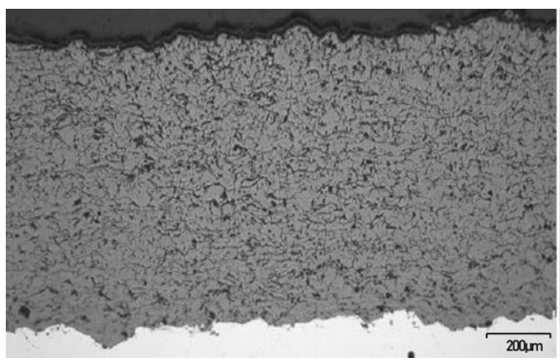

(a)

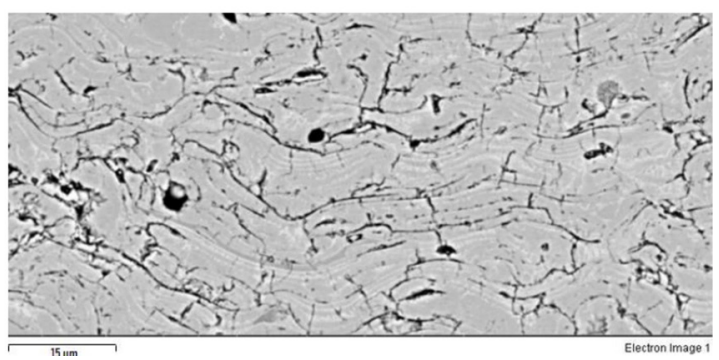

(b)

Fig. 2. Optical (a) and SEM (b) micrographs of $\mathrm{Cr}_{2} \mathrm{O} 3$ APS coatings

In the layered structure of the chromia coating light coloured stringers are observed (Fig. 2b), which are attributed to sub-stoichiometric chromium oxide $\left(\mathrm{CrO}_{2}\right)$ [17]. The presence of this phase in the coating was not confirmed by the X-ray diffraction of the asplasma-sprayed $\mathrm{Cr}_{2} \mathrm{O}_{3}$ coating (Fig. 3b), indicating small volume fraction of the $\mathrm{CrO}_{2}$ suboxide. EDS analysis revealed metallic $\mathrm{Cr}$ areas within particles and variable $\mathrm{Cr} / \mathrm{O}$ ratios (Fig. 3). No changes of crystallographic structure of $\mathrm{Cr}_{2} \mathrm{O}_{3}$ during spraying were observed. The crystallographic structure remained as $\alpha-\mathrm{Cr}_{2} \mathrm{O}_{3}$ (eskolaite) without signs of other crystalline or amorphous phases. As observed by others [7,18-19] at plasma temperatures, a reduction of $\mathrm{Cr}_{2} \mathrm{O}_{3}$ to $\mathrm{Cr}$ occurs leading to small amounts of other phases, like $\mathrm{Cr}_{3} \mathrm{O}_{4}, \mathrm{CrO}$, $\mathrm{CrO}_{2}$, along with oxidation of chromium thus leading to a stable escolaite phase.

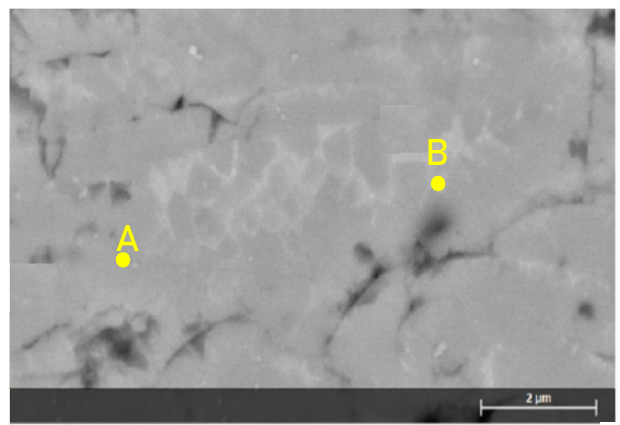

A

B

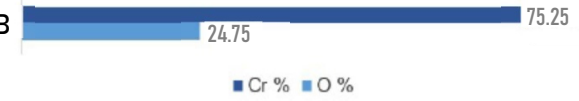

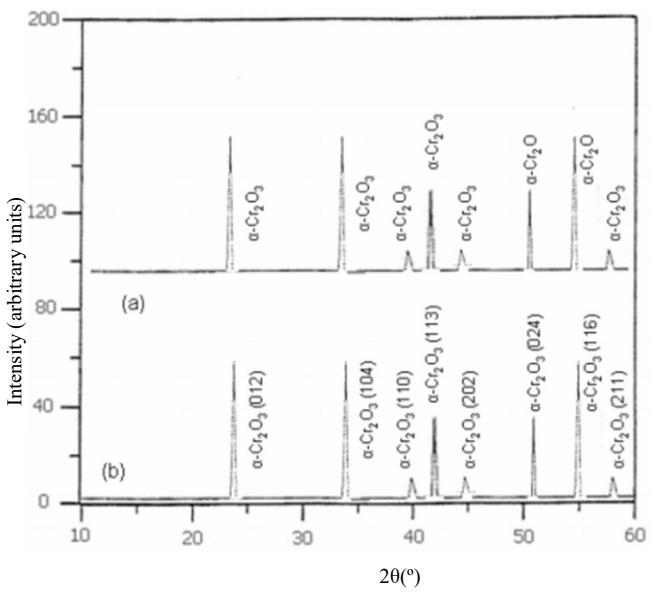

$2 \theta\left({ }^{\circ}\right)$

Fig. 3. $\mathrm{SEM} \mathrm{Cr}_{2} \mathrm{O} 3$ coating with EDS analysis and $\mathrm{XRD}$ patterns of $\mathrm{Cr}_{2} \mathrm{O}_{3}$ powder (a) and coating (b)

Fig. 4 shows the cross section of the titania coating which also exhibits acceptable porosity $(\sim 6 \%)$, good coating integrity and scattered transverse cracks emanating either from interconnected pores or local thermal stresses. XRD analysis of the titania coating shows presence of rutile only, while the titania powder exhibits phases of rutile along with anatase and magneli which are transformed during spraying to rutile, as reported and elsewhere $[20,21]$. According to literature metastable anatase transforms to stable rutile phase above $620^{\circ} \mathrm{C}$, while magneli phase undergoes oxidation to form rutile phase under similar condition $[22,23]$. 

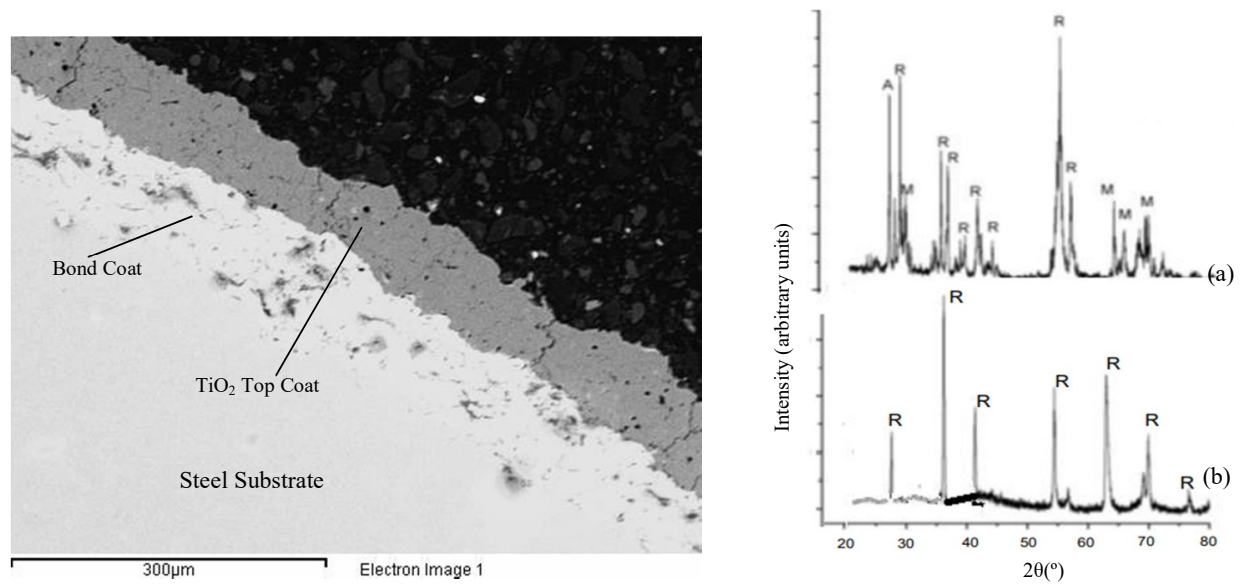

Fig. 4. Titania APS Coating (left) and XRD patterns of $\mathrm{TiO} 2$ powder (a) and coating (b)

\subsection{Fatigue results}

Fig. 5 shows imprint diameter as function of impact cycles for $100 \mathrm{~N}$ indentation force. It is obvious that the increase in coating thickness increases the overall durability of both types of material. The significant observation is that chromia coatings exhibit better strength characteristics than their titania counterparts. In addition, the increase in strength for chromia coatings as function of the thickness increase is more intense than the one obtained by titania coatings.

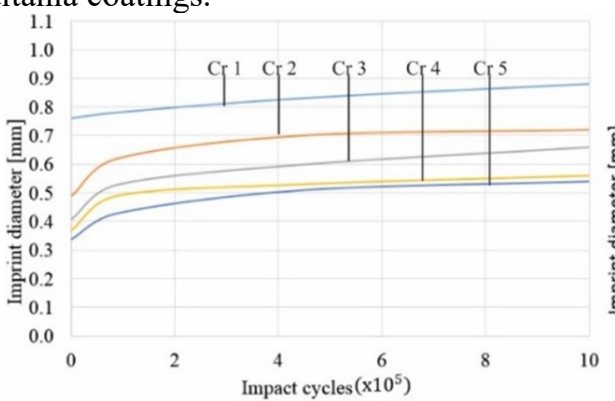

a)

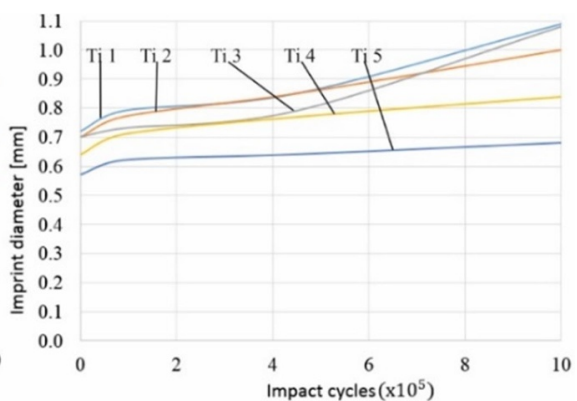

b)

Fig. 5. Imprint diameter obtained at $100 \mathrm{~N}$ indentation force for (a) chromia and (b) titania coatings

Fig. 6 shows the results for the imprint diameter obtained at $250 \mathrm{~N}$. The results here tell another story. Despite that the small differences between the two types during high cycling fatigue, the titania coatings are characterized by better strength at the very low cycling fatigue loading. The story begins to change at $4.5 \times 10^{5}$ impact cycles where the chromia coatings reach the performance of their titania counterparts. At very high cycling fatigue loading, the extent of the imprint gets stabilized. The phenomenon is more intense for titania coatings which is attributed to strain hardening [24]. 

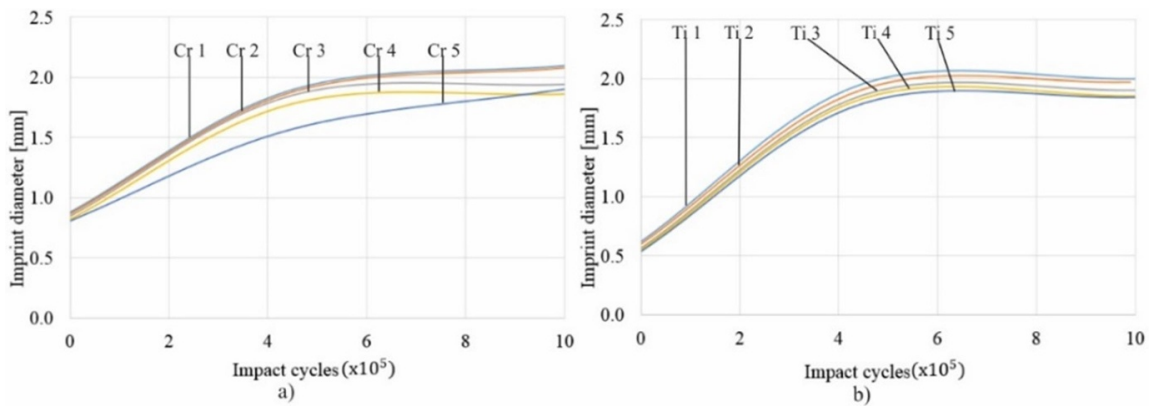

Fig. 6. Imprint diameter obtained at $250 \mathrm{~N}$ indentation force for (a) chromia and (b) titania coatings

At very low cycling fatigue tests at $250 \mathrm{~N}$ indentation force as it is shown in Fig. 7 the Chromia coatings exhibited slightly better mechanical strength than titania coatings [25]. At middle impact cycles range, the first two titania specimens are characterized by shallower imprints than their counterparts. Although the fourth and fifth chromia imprints indicated that the specimens are characterized by higher resistance than the titania coatings. Taking into consideration the first four specimens from each category, the titania coated specimens exhibit higher strength against the indentation loads [26].
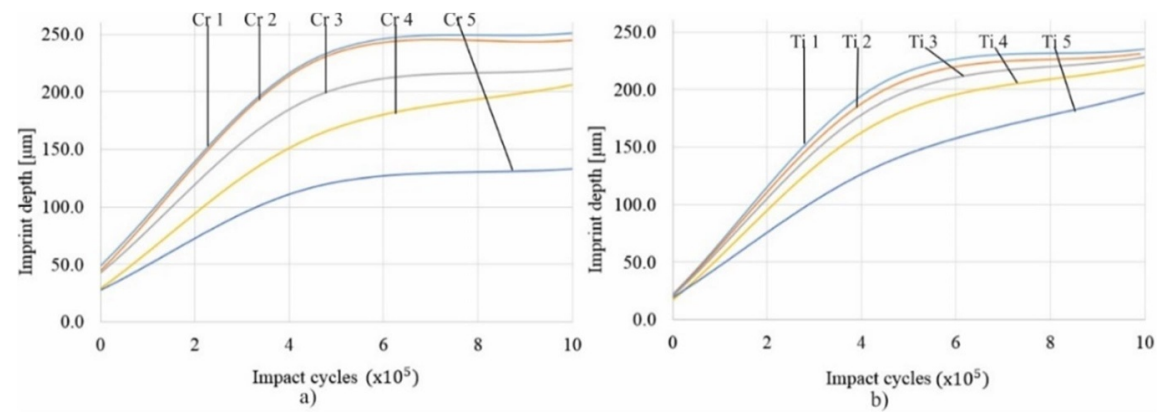

Fig. 7. Imprint depth obtained at $250 \mathrm{~N}$ indentation force for (a) chromia and (b) titania coatings

Fig. 8 shows the remaining imprints at $4.5 \times 10^{5}$ and $10 \times 10^{5}$ impact cycles for the chromia and titania coatings with impact force of $100 \mathrm{~N}$. The first notation is that in agreement with Fig 5, the remaining imprints at the $1 \times 10^{6}$ impact cycles are slightly larger than those obtained where the number of impact cycles was set equal to $4,5 \times 10^{5}$. Furthermore, the size of the imprints left on coated substrates for $4.5 \times 10^{5}$ impact cycles, indicate that indeed the difference between chromia and titania coatings is distinct. In addition, one may observe that when moving from specimen 1 to 5 (for chromia) and 10 to 6 (for titania) for impact cycles equal to $4.5 \times 10^{5}$, the extent of the imprint decreases. Although this observation is very much less distinct for titania coatings as can be verified by Fig. 5b. When the number of impact cycles was set equal to $1 \times 10^{6}$, the differences in extent of the remaining imprints for chromia coatings when moving from specimen 1 to 5 gets more intense, than the one observed on titania. This also can be clarified by Fig. 6, since the data expressed by Y-axis vary in shorter bounds than those obtained for chromia. 

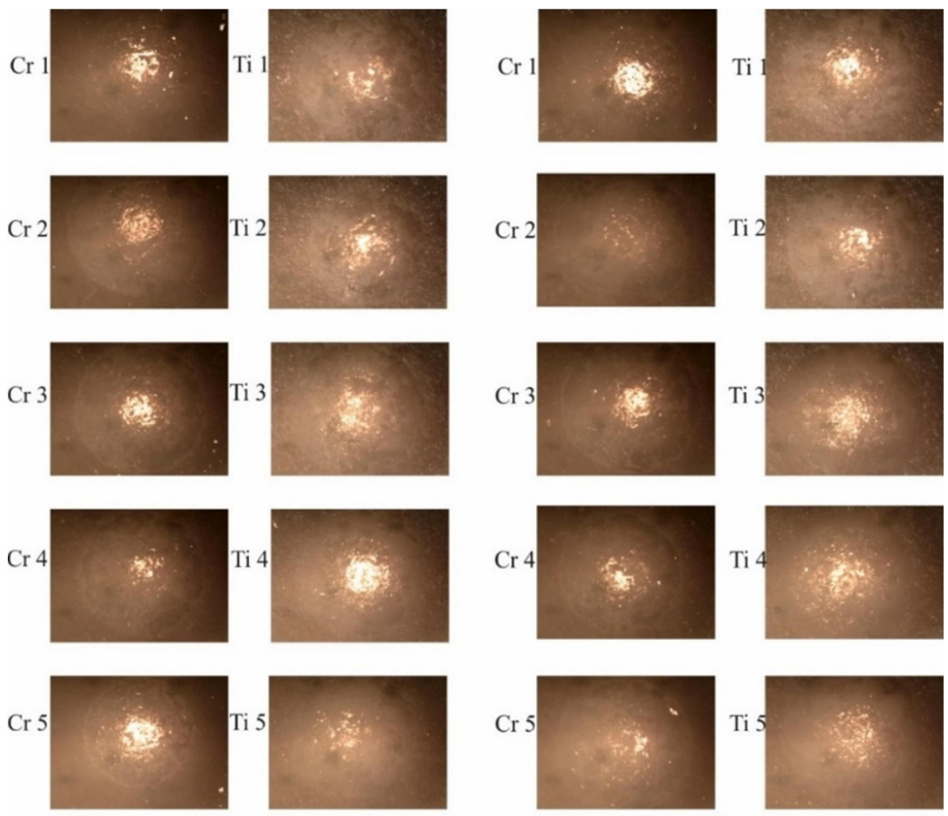

a) $4.5 \times 10^{5}$ impact cycles

b) $1 \times 10^{6}$ impact cycles

Fig. 8. Comparison for both types of specimens at $4.5 \times 10^{5}$ impact cycles, and $10 \times 10^{5}$ impact cycles at $100 \mathrm{~N}$ impact force

Fig. 9 indicates the extent of the imprint diameter for both chromia and titania coatings, while Fig. 10 represents the imprints at on the chromia and titania coatings after the $600 \mathrm{~N}$ and $1500 \mathrm{~N}$ static load. The imprints are characterized by a conical shape with pressure tip in the middle as a result of the conical indenter. In Fig. 9a can be noticed that the imprint depth left on titania coatings is quite larger than the chromia coatings after $600 \mathrm{~N}$ indentation force [27]. The difference in imprint depth between the two types of coatings exhibits a decrease after the introduction of $1500 \mathrm{~N}$ indentation force. Investigating the remaining imprint diameter, the results indicated that all chromia and titania specimens exhibited similar deformation characteristics in radial direction after $600 \mathrm{~N}$ of indentation load. According to the Vickers test findings, the coatings that can withstand the most desired static load resistance are the chromia.

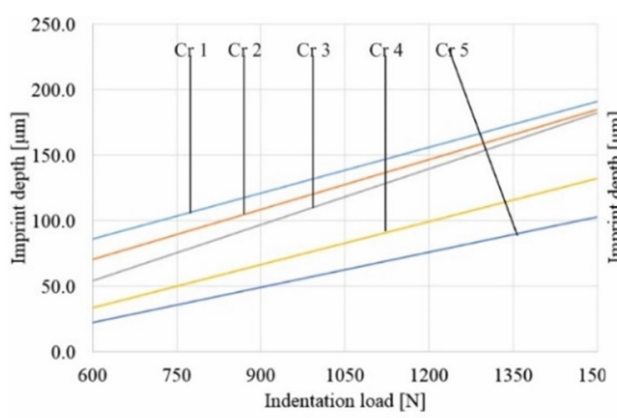

a) Chromia coatings

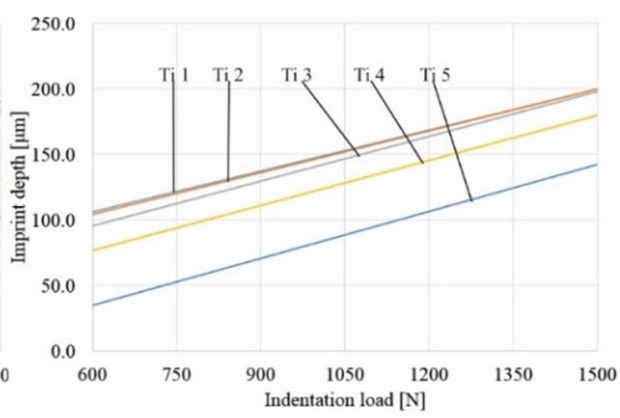

b) Titania coatings

Fig. 9. Imprint depth after $600 \mathrm{~N}$ and $1500 \mathrm{~N}$ static loading for a) chromia and b) titania coatings 


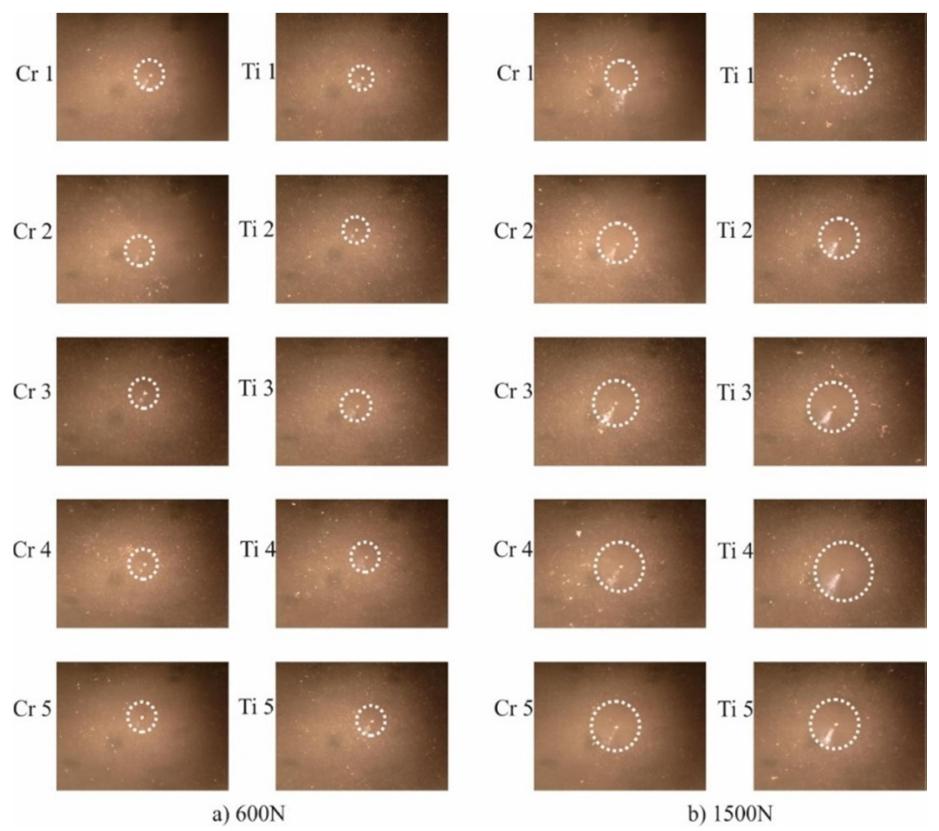

Fig. 10. Imprints on chromia and titania coatings a) After $600 \mathrm{~N}$ and b) After $1500 \mathrm{~N}$ static load

\section{Conclusions}

Chromia $\left(\mathrm{Cr}_{2} \mathrm{O}_{3}\right)$ and titania $\left(\mathrm{TiO}_{2}\right)$ powders were deposited by atmospheric plasma spraying (APS) on the surface of carbon steel with an intermediate layer of $\mathrm{Ni}$-Al bond APS coating. The coating microstructures exhibited typical lamellar structure, with porosity within quality limits.

XRD of titania coating revealed that anatase and magneli phases, which were traced in the $\mathrm{TiO}_{2}$ powder, had transformed upon spraying into rutile phase while no phase transformation observed during spraying for the chromia coating.

Cyclic fatigue tests were conducted, using an in-house-built test apparatus for $1 \times 10^{3}$, $4.5 \times 10^{5}$ and $1 \times 10^{6}$ impact cycles under the two different cases of $100 \mathrm{~N}$ and $250 \mathrm{~N}$ impact force by measuring the imprints diameters.

The mechanical strength of five chromia and five titania plasma sprayed coatings was investigated by means of cyclic and static loading test conditions. The static tests were employed according to Vickers tests standards with $600 \mathrm{~N}$ and $1500 \mathrm{~N}$ indentation loads.

In low number of cycling fatigue tests $\left(1 \times 10^{3}\right)$ at $250 \mathrm{~N}$ impact force titania coatings exhibited better strength, while at $4.5 \times 10^{5}$ impact cycles, both types of coatings exhibited quite similar strength characteristics. Quite similar characteristics also obtained at high number $\left(1 \times 10^{6}\right)$ of impact cycles, where the difference of both types of coating imprints' diameter are much less than before.

The imprint depth at $100 \mathrm{~N}$ cyclic fatigue test exhibited similar results. For both types of coatings, at low impact force the thickness of the coatings plays critical role with better performance obtained by chromia coatings.

The parameters that are affecting the mechanical strength and behaviour of the specimens are the substrate material, the bonding layer between coating and substrate, the different thicknesses of the specimens, the adhesion properties of the coating materials which is depended on the amount of porosity and the strain hardening mechanism after cyclic loading. The combination of the above parameters can explain the different behaviour of the specimens. The most important parameter for the evaluation of the 
mechanical strength and behaviour of the specimens, is the strain hardening mechanism which is different under various parameters, cyclic loads and number of impacts.

During static loading, at $600 \mathrm{~N}$ and $1500 \mathrm{~N}$ both types of coatings exhibited similar characteristics at the crater diameter but with grater damage (larger crater depth) for titania. Summarizing all the above, chromia coatings exhibited higher strength resistance than titania coatings with better mechanical properties and coating structure. The reason for this behaviour is because of the two intensive static loads that affect both substrate and coating materials and without any strain hardening within coating, the specimens demonstrate typical strength behaviour.

\section{References}

1. P. Fauchais, M. Fukumoto, A. Vardelle, M. Vardelle, J. Therm. Spray Technol. 13, 337 (2004)

2. E. Balić, M. Hadad, P.P. Bandyopadhyay, J. Michler, Acta Mater. 57, 5921 (2009)

3. H. Ahn, O. Kwon, Wear, 225-229 (2), 814 (1999)

4. B. Wang, Z. Shui, Wear, 138, 93 (1990)

5. C. Richard, J. Lu, G. Béranger, F. Decomps, J. Therm. Spray Technol., 4, 342 (1995)

6. Y. Song, X. Zhuan, T.J. Wang, X. Chen, Mech. Mater. 74, 26 (2014)

7. P. Ctibor, K. Neufuss, P. Chraska, J. Therm. Spray Technol., 15, 689 (2006)

8. O. Kováŕík, J. Siegl, Z. Procházka, J. Therm. Spray Technol., 17 525-532 (2008)

9. A. Ibrahim, C. Berndt, Mat. Sci. Eng. A, 456 114-119 (2007)

10. H. Voorwald, R. Souza, W. Pigatin, M. Cioffi, Surf. Coat. Technol, 190, 155-164 (2005)

11. J.A.M. de Camargo, H.J. Cornelis, V.M.O.H. Cioffi, M.Y.P. Costa, Surf. Coat. Technol., 201, 9448- 9455 (2007)

12. A. Ibrahim, R. Lima, C. Berndt, B. Marple, Surf. Coat. Technol., 201, 7589- 7596 (2007)

13. A. Vackel, G. Dwivedi, S. Sampath, Thermal Spray Coatings, JOM, DOI 1-14 (2015)

14. T. Varis, T. Suhonen, A. Ghabchi, A. Valarezo, S. Sampath, X. Liu, S.-P. Hannula, J. Therm. Spray Technol., 23, 1009-1018 (2014)

15. A. Valarezo, W.B. Choi, W. Chi, A. Gouldstone, S. Sampath, J. Therm. Spray Technol., 19 852-865 (2010)

16. M. Costa, M. Venditti, H.J.C. Voorwald, M. Cioffi, T. Cruz, Mat. Sci. Eng. A, 507 2936 (2009)

17. I. Lyo, H. Ahn, D. Lim, Surf. \& Coat. Technol, 41, 163 (2003)

18. D. Steduto: Deposition and properties of chromium oxide based coatings by plasma spray process, MSc thesis, School of Materials Science and Environmental Engineering, Tampere University, Tampere (2020)

19. S. Kar, S. Paul, P. Bandyopadhyay, Surf. \& Coat. Technol, 304 (25), 364 (2016)

20. S. Yoganarasimhan, C. Rao, Trans. Faraday Soc. 58, 1579 (1962)

21. S. Miao, M. Lei, Nuclear Instruments and Methods in Physics Research, B 243, 335 (2006)

22. R. Lima, B. Marple, Acta Materialia, 52, 1163 ( 2004) 
23. P. Ctibor, K. Neufuss, P. Chraska, J. Therm. Spray Technol., 15, 689 (2006)

24. L. Berger, Titanium Oxide-New Opportunities for an Established Coating Material, in Proceedings of the International Thermal Spray Conference, C. Berndt (Ed.), DVS Verlag, Düsseldorf (2003)

25. J. Kiilakoski, C. Langlade, H. Koivuluoto and P. Vuoristo, Surf. \& Coat.Technol., 371, 245 (2019)

26. S. Barbhuiya, A. Ikbal Choudhury: Characterization of Mechanical Properties and the Abrasive Wear of Thermal Spray Coatings, in Thermal Sprayed Coatings and their Tribological Performances, IGI Global, 328 (2015)

27. A. Koutsomichalis, N. Vaxevanidis, A. Katikas, A. Tzanis: Tensile, fatigue and wear behaviour of titania plasma sprayed coatings, in Proceedings of $13^{\text {th }}$ International Conference on Tribology, Kragujevac, Serbia (2013) 